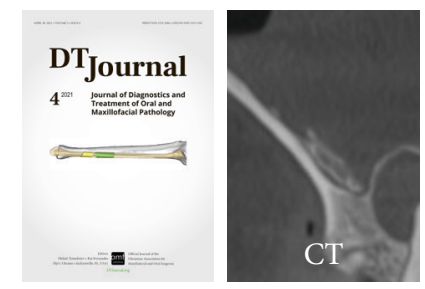

\title{
CASE
}

\section{Lateral Sinus Membrane Elevation in Case of Lateral Intra-sinus Linear Calcification: Expanding the Indications}

Ivan V. Nagorniaka,* \& Maksym 0. Zhaldak

\section{SUMMARY}

Intra-sinus calcifications (ISCs) which are noted only in 2.4 percent of maxillary sinus pathology can be a challenging condition for the implantologists. A few studies describe only a recommendation for the centrally localized calcification spots in the maxillary sinus. Simultaneously, there is no publications focused on lateral sinus lift performance in cases of laterally, peripherally located linear ISCs. The purpose of our report is to present a surgical tactic for lateral approach of Schneiderian membrane elevation in a 58-year-old female with linear and fine punctate calcifications, inta-sinus hyperostosis, and mucosal swelling with height above the middle level of the sinus.

Kyiv, Ukraine

a PhD, Surgeon Dentist Doctor, Private Clinic.

b Surgeon Dentist Doctor, Private Clinic "Dentistry Troyanda" LLC.

* Corresponding author's address: Private Practice (certificate for management system according to ISO 9001:2015 - Private Entrepreneur Nagorniak I.V.), 6-G Andruschenka Street, Office 6, Kyiv 01135, Ukraine. E-mail: ivan.nagorniak@gmail.com (Ivan Nagorniak)

Please cite this article as: Nagorniak IV, Zhaldak MO. Lateral sinus membrane elevation in case of lateral intra-sinus linear calcification: expanding the indications. J Diagn Treat Oral Maxillofac Pathol 2021;5(4):52-6.
Abbreviation ' $\mathrm{CT}$ ' at the upper right icon means that article contains computed tomography scans.

Paper received 27 March 2021

Accepted 11 April 2021

Available online 30 April 2021

https://dx.doi.org/10.23999/j.dtomp.2021.4.2

(C) 2021 OMF Publishing, LLC. This is an open access article under the CC BY license (http://creativecommons.org/licenses/by-nc/4.0/). 


\section{INTRODUCTION}

Intra-sinus calcification (ISC) is a single or multiple calcifications in the area of paranasal sinus pathology visualized on the computed tomography (CT) as a radiodencities. According to Yoon et al, the ISC mostly occurs in the case of maxillary sinus infection. ${ }^{1,2}$ Among total number of patients (510 persons) with chronic maxillary sinusitis, authors' examination noted the presence of ISC in 51 percent of fungal and in 3 percent non-fungal sinusitis. ${ }^{1}$ Korean authors meticulously described four shape patterns of the ISCs and three forms of its localization what is helpful in pre-implantation planning.

There is a need to differentiate ISC from other radiopaque lesions (like osteoblastic osteitis of the maxillary sinus walls, ${ }^{2,3}$ reactional osteogenesis, ${ }^{4}$ maxillary antrolith, ${ }^{5,6}$ etc) located at the periphery of the maxillary sinus and within its walls.

A very few English literature sources present recommendations for the planned implantation with or without sinus lift in case of calcification spots in maxillary sinus. ${ }^{7,8}$ Those studies describe only recommendations for the centrally localized calcification spots in the maxillary sinus.7,8 Simultaneously, there is no publications focused on lateral sinus lift performance in cases of presence of laterally, peripherally located linear intra-sinus calcifications.

The purpose of our report is to present surgical tactic for lateral approach of Schneiderian membrane elevation in a 58-year-old female with linear and fine punctate calcifications, intra-sinus hyperostosis, and mucosal swelling with height above the middle level of the sinus.

\section{CASE REPORT}

A 58-year-old Caucasian female presented with unsuccessfully treated periapical lesion of the tooth 1.6. A cone-beam CT (Fig 1) showed smoothly marginated linear calcification (measured $10.04 \mathrm{~mm}$ in a anteroposterior direction and 1.08 to $1.7 \mathrm{~mm}$ in thickness) located at the lateral wall of the right maxillary sinus. Multiple fine punctate calcifications along the lateral and medial walls were also noted. Linear calcification presented as a mixed calcification structure. The density of ISCs varied from 450 to 842 Hounsfield units (HU). Also, a hyperostosis was visualized along the inferior wall of the sinus. Mucosal inflammatory changes around the calcifications and periapical lesion visualized as two rounded swellings ${ }^{9}$ measured $17.60 \times 27.60 \times 28.04 \mathrm{~mm}$ the lateral one and $21.20 \times 17.40 \times 21.40 \mathrm{~mm}$ the inferior one. Mucosal thickening along the medial, inferior, and lateral right maxillary sinus walls varied from 1.72 to $2.24 \mathrm{~mm}$ with no obstruction of the wide ostium. At the pre-implantation planning we concluded that inferior sinus wall hyperostosis appeared as a result of prolonged intra-sinus periosteal reaction for the chronic periapical infection of the tooth 1.6.

Surgery included a tooth 1.6 removal (Fig 2) and formation of the lateral bony window. After the osteotomy of the lateral maxillary sinus wall, a thin layer of the fibrotic tissue was visualized between inner surface of the sinus and lateral linear calcification. Fibrotic tissue in the area of bony window was removed by bur. Then, a a controlled perforation of the linear lateral calcification (ie, calcificationtomy) was done. Schneiderian membrane was elevated, bone grafting performed after the insertion of the collagen membrane and the flap was sutured.

A post-operative period was smooth.

\section{DISCUSSION}

Intra-sinus calcifications which are noted only in 2.4 percent of maxillary sinus CT findings can be a challenging condition for the implantologists. ${ }^{7}$ As upon the sinus lift procedure it is crucial to avoid perforations. ${ }^{10}$ Perforations ' avoidance in case of linear calcifications can be problematic for inexperienced doctor. That is why understanding the anatomical variants of ISCs and types of perforations ' management are so important.

Yoon et al described four shape-related patterns of the ISC:

1. Fine punctate.

2. Irregular nodular.

3. Round or eggshell.

4. Smoothly marginated linear.

Yoon et al's classification of ISC localization: 1 ) central, 2) peripheral, and 3) mixed.

Authors emphasized that ISC can also occur in such intra-sinus inflammatory disease as a mucocele. It can be proved by our case with a presence of two rounded swellings. Moreover, the peripheral location of the calcifications in our particular case proved 

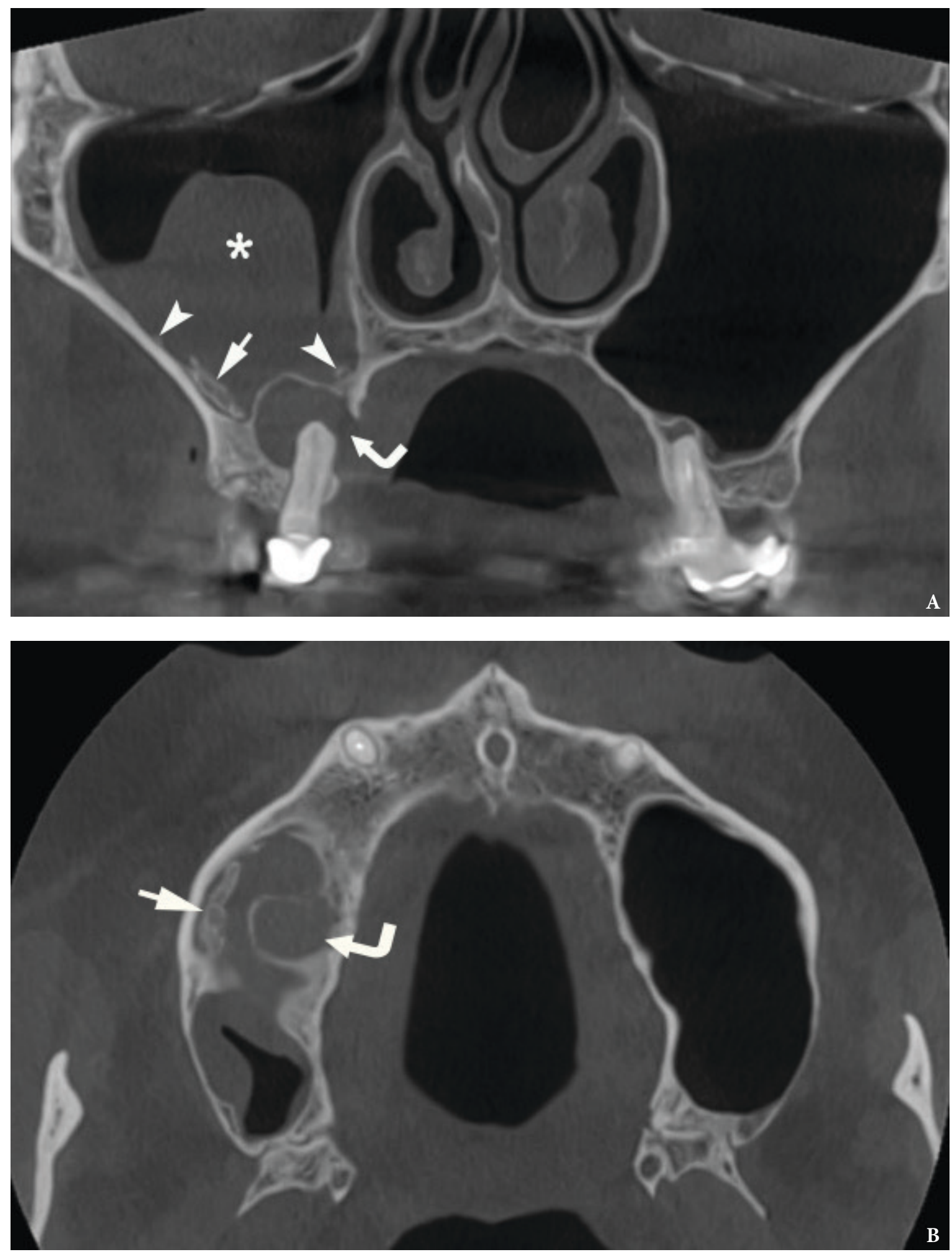

FIGURE 1. A coronal (A) and axial (B) cone-beam computed tomography scans in a 58-year-old Caucasian female. Arrow indicates on a smoothly marginated linear calcification (measured $10.04 \mathrm{~mm}$ in a anteroposterior direction and $2.21 \mathrm{~mm}$ in thickness) located at the later wall of the right maxillary sinus. Arrowheads label the fine punctate calcifications. Notes periapical lesion (curved arrow) at the palatal root of the tooth 1.6 and mucosal inflammatory changes (asterisk) around the calcifications. 

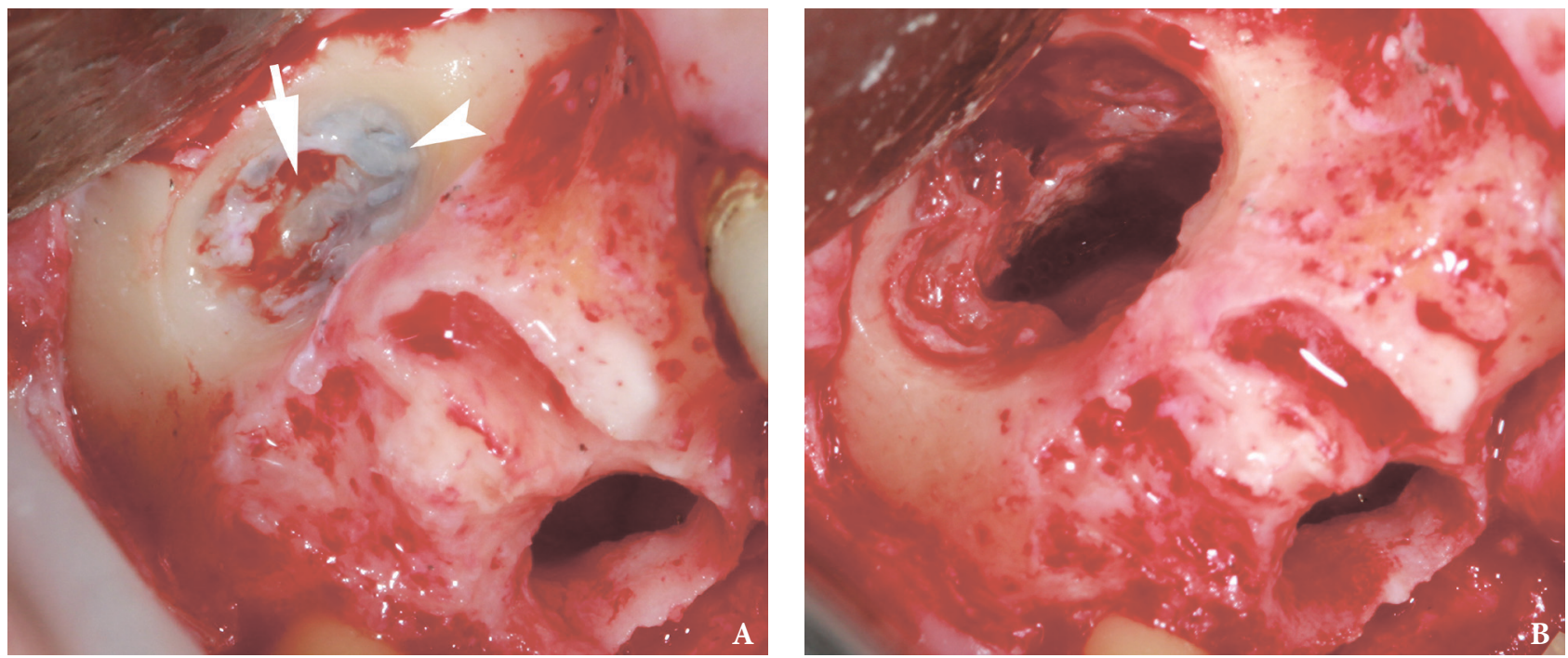

FIGURE 2. Intraoperative view after the tooth 1.6 removal $(\mathbf{A})$ demonstrates formation of the lateral bony window for Schneiderian membrane elevation in the area of lateral linear intra-sinus calcification (arrow). Bur-perforated thin layer of the fibrotic tissue visualized between inner surface of the sinus and linear calification is indicated by arrowhead. Image B shows elevated sinus floor after the "calcificationtomy."

the statement of the Momeni et al, that peripherally localized calcifications is typical for a non-fungal sinusitis.

Discussing the rare sinus "stones," some authors mention that such sialoths may be a dystrophic calcification. ${ }^{1}$

Chen et al proposed six groups' classification of maxillary sinus conditions facilitating the preimplantation and pre-sinus lift sinonasal evaluation. To the Group 6 of the their classification the CT findings belong with calcification spots in a maxillary sinus.

\section{CONCLUSIONS}

Summarizing, in that case we present not only rare intra-sinus pathology like calcification. But we applied a new technique to this pathology as well, one of the steps in which can be named as "calcificationtomy" (ie, perforation of the intra-sinus calcification in the area of lateral sinus lift).

Thus, our case (in which we had the height of the dome-shaped swellings exceeding middle level of the sinus) can help to expand the indications for the patients of Chen Group 6 maxillary conditions. Further studies with a larger number of cases are needed.

\section{ROLE OF CO-AUTHORS}

Conceptualization: Nagorniak IV. Data and interpretation acquisition: Zhaldak MO, Nagorniak IV. Drafting the manuscript: Nagorniak IV. Critical revision of the manuscript: Nagorniak IV, Zhaldak MO. Approval of the final version of the manuscript: all authors.

\section{REFERENCES}

1. Yoon JH, Na DG, Byun HS, Koh YH, Chung SK, Dong HJ. Calcification in chronic maxillary sinusitis: comparison of CT findings with histopathologic results. AJNR Am J Neuroradiol 1999;20(4):571-4.

2. Tovi F, Benharroch D, Gatot A, Hertzanu Y. Osteoblastic osteitis of the maxillary sinus. Laryngoscope 1992;102(4):426-30. https://doi.org/10.1288/00005537-199204000-00010

3. Momeni AK, Roberts CC, Chew FS. Imaging of chronic and exotic sinonasal disease: review. AJR Am J Roentgenol 2007;189(6 Suppl):S35-45. https://doi.org/10.2214/AJR.07.7031

4. Estrela C, Porto OC, Costa NL, Garrote Mda S, Decurcio DA, Bueno MR, Silva BS. Large reactional osteogenesis in maxillary sinus associated with secondary root canal infection detected using cone-beam computed tomography. $J$ Endod 2015;41(12):2068-78.

https://doi.org/10.1016/j.joen.2015.09.004

5. Shenoy V, Maller V, Maller V. Maxillary antrolith: a rare cause of the recurrent sinusitis. Case Rep Otolaryngol 2013;2013:527152.

https://doi.org/10.1155/2013/527152 
1. Som PM, Lidov M. The significance of sinonasal radiodensities: ossification, calcification, or residual bone? AJNR Am J Neuroradiol 1994;15:917-22.

2. Chen YW, Lee FY, Chang PH, Huang CC, Fu CH, Huang CC, Lee TJ. A paradigm for evaluation and management of the maxillary sinus before dental implantation. Laryngoscope 2018;128(6):1261-7. https://doi.org/10.1002/lary.26856

3. Chen YW, Huang CC, Chang PH, Chen CW, Wu $\mathrm{CC}, \mathrm{Fu} \mathrm{CH}$, Lee TJ. The characteristics and new treatment paradigm of dental implant-related chronic rhinosinusitis. Am J Rhinol Allergy 2013;27(3):237-44. https://doi.org/10.2500/ajra.2013.27.3884

4. Wayoff MR. Mucosal swellings, mucoceles, and polyps in paranasal sinuses. In: Gershwin ME, Incaudo GA, editors. Diseases of the sinuses. Totowa, NJ: Humana Press, 1996:273-90.

https://doi.org/10.1007/978-1-4612-0225-7_12

5. Nagorniak IV. Sinus lift: analysis of Schneiderian membrane perforations. J Diagn Treat Oral Maxillofac Pathol 2020;4(10):191-3.

https://doi.org/10.23999/j.dtomp.2020.10.2 